\title{
Game Reproduction of the Queuing System as an Economic Laboratory Experiment
}

\author{
Rinat Faizullin* \\ Department of Information Technologies in Public Administration, Institute of Management \\ Technologies, MIREA — Russian technological university Moscow, Russia
}

\begin{abstract}
This article presents the results of an economic laboratory experiment based on a queuing system. The "classical" problem of the theory of mass service, known as the Erlang problem, with the aim of studying the behavioral theory of games reproduced in this article. It is based on the theory of queuing, which allows the company to avoid inefficient organization of customer service. Considerable attention is paid to the provisions of the behavioral theory of games as a method of making management decisions and their practical application. A mathematical model of decision making studied by queuing theory was compiled. There are Conclusions about the behavior in real economic situations. The experiment presented in the form of a game can be used as an original method of teaching economics.
\end{abstract}

\section{Introduction}

The studying of behavioral Economics contributes to a deeper and more advanced understanding of the economic phenomena considering their psychological components.

The development of behavioral economics had led to the development of behavioral game theory - a branch of game theory that deals with the reproduction of economic situations in order to study it in favorable conditions. "Game theory proves the following: if economic entities do not change their strategy, they will come to an equilibrium state in which the gain can no longer be increased by continuing to follow the chosen line of behavior. For example, Nash equilibrium is a situation in a non-cooperative game in which none of the players can increase their winnings by making moves on a unilateral basis (i.e., without cooperating with other players)»[1].

Subsequently, social experiments develop; the laboratory economic experiment is one of their varieties. "An economic experiment is an artificially reproduced economic phenomenon in which economic processes are observed and controlled. Economic experiments are used to test hypotheses, theories, and practical recommendations for the economic system managing, and also to study the behavior of individuals or collectives" [2].

The use of laboratory economic experiments allows you to test some hypotheses without wasting time and money. Charness et al (2018) published experimental data to

\footnotetext{
* Corresponding author: rf85@mail.ru
} 
explore the question: "How do People Choose Between Biased Information Sources?" [3], Sauer et al (2019) studied the interaction of the municipality and the industrial enterprise in the use of wastewater treatment plants [4]. Angelovski et al (2021) published the experiment "Equal and unequal profit sharing in highly interdependent work groups" [5].

The complex nature of the market economy stimulates using of more serious methods of analyzing its theoretical and practical problems [6]. Using of mathematical tools becomes an effective method of studying economic phenomena and processes [7], adding validity and objectivity.

Queuing theory is a branch of economic and mathematical modeling; this section is the theoretical basis for the effective organization and operation of Queuing systems. Queuing systems (QS) are encountered in many areas of the economy and are intended for multiple using when performing the same type of tasks. An economic experiment, presented as a game that simulates the real behavior of QS participants, can be used as an original methodology of teaching economic disciplines. Actually, the game reproduction of the Queuing system as a laboratory economic experiment will facilitate the understanding of the QS functioning as one of the ways to describe economic situations and the understanding of certain aspects of behavioral Economics.

The purpose of the article is the analysis of the economic laboratory experiment results to develop recommendations for the efficient construction of the QS.

Obviously, due to incorrect or inefficient functioning of the customer service system the company may lose customers, what will affect the results of the company's activities.

"Each QS is intended to serve a certain flow of requests. It also includes in its structure a number of service "devices", which are called service channels. According to the number of channels QS is divided into single-channel and multichannel" [8]. There are also systems with and without failures, with and without queues.

The use of a queuing system is relevant both in technology [9] and in economics [10].

Different ways of organizing customer service systems correspond to different tasks of the QS. "A multichannel system with failures is known as the Erlang problem. This is one of the first "classical" problems of Queuing theory. This problem consists in the fact that there are $\mathrm{n}$ channels (communication lines), which receive a flow of requests with an intensity of $\lambda$. The service flow of each channel has an intensity of $\mu$ " [5]. Based on the known formulae you can calculate the Q - relative throughput QS (the probability that the incoming system request is serviced), A - absolute throughput QS (the number of served clients).

\section{Methodology}

The following game is proposed as part of an economic laboratory experiment based on QS. Several teams (let us call them "businessmen") take part in the game. The number of teams is preferably from 3 to 8 , each consists of 1 to 3 people. Teams are invited to offer single hotel rooms for daily rent. It is known that every businessman has an initial capital of 100,000 rubles, and the cost of maintaining one room is 10,000 rubles per month. It is also known in advance that each single room is offered at a price of 1,000 rubles per day. In total, 750 people are ready to rent such rooms per month, and everyone is ready to rent a room for a day, i.e. the total demand is 750 bed-days. Calculations for the game are presented in table $1(\mathrm{~N}$ - the total number of rooms opened by the teams; $\mathrm{Q}$ - the relative capacity of the QS; A - the absolute capacity of the QS, the number of served clients).

Obviously, the number of rooms that will be opened by the businessmen is limited. If a guest of the hotel wants to rent a room, but none of them is available, then he receives a refusal of service and leaves. Based on the amount of available to the player money and some his own reflections, the player decides how many rooms can be opened. Players 
report their decision to the host. The host announces the total number of rooms opened during this move, and, according to table 1, the teams become aware of the number of served clients. Accordingly, each player can calculate their financial result. Then the moves are repeated and their number is discussed in advance. The winner is the one whose profit at the end of the game will be greater.

It is important that none of the participants in the game knows about the intentions of other players.

Table 1. Dependence of the number of served clients on the number of open numbers*

\begin{tabular}{|c|c|c|c|c|c|}
\hline $\boldsymbol{N}$ & $\boldsymbol{Q}$ & $\boldsymbol{A}$ & $\boldsymbol{N}$ & $\boldsymbol{Q}$ & $\boldsymbol{A}$ \\
\hline 2 & 0,076809 & 57,60709 & 28 & 0,917193 & 687,8951 \\
\hline 3 & 0,115032 & 86,27379 & 29 & 0,933371 & 700,0285 \\
\hline 4 & 0,153115 & 114,836 & 30 & 0,947397 & 710,5476 \\
\hline 5 & 0,191043 & 143,2822 & 31 & 0,959304 & 719,4784 \\
\hline 6 & 0,228799 & 171,599 & 32 & 0,969186 & 726,8897 \\
\hline 7 & 0,266362 & 199,7714 & 33 & 0,977189 & 732,8916 \\
\hline 8 & 0,30371 & 227,7822 & 34 & 0,983504 & 737,6278 \\
\hline 9 & 0,340815 & 255,6115 & 35 & 0,988354 & 741,2656 \\
\hline 10 & 0,377649 & 283,2367 & 36 & 0,991978 & 743,9831 \\
\hline 11 & 0,414176 & 310,6318 & 37 & 0,994609 & 745,9565 \\
\hline 12 & 0,450356 & 337,7667 & 38 & 0,996466 & 747,3492 \\
\hline 13 & 0,486143 & 364,6072 & 39 & 0,997739 & 748,3046 \\
\hline 14 & 0,521485 & 391,1135 & 40 & 0,998589 & 748,9419 \\
\hline 15 & 0,55632 & 417,2402 & 41 & 0,99914 & 749,3554 \\
\hline 16 & 0,59058 & 442,9353 & 42 & 0,999489 & 749,6165 \\
\hline 17 & 0,624186 & 468,1392 & 43 & 0,999703 & 749,7771 \\
\hline 18 & 0,657046 & 492,7842 & 44 & 0,999831 & 749,8734 \\
\hline 19 & 0,689058 & 516,7938 & 45 & 0,999906 & 749,9297 \\
\hline 20 & 0,72011 & 540,0824 & 46 & 0,999949 & 749,9618 \\
\hline 21 & 0,750074 & 562,5552 & 47 & 0,999973 & 749,9797 \\
\hline 22 & 0,778812 & 584,1088 & 48 & 0,999986 & 749,9894 \\
\hline 23 & 0,806177 & 604,6329 & 49 & 0,999993 & 749,9946 \\
\hline 24 & 0,832017 & 624,0127 & 50 & 0,999996 & 749,9973 \\
\hline 25 & 0,856177 & 642,1326 & 51 & 0,999998 & 749,9987 \\
\hline 26 & 0,87851 & 658,8821 & 52 & 0,999999 & 749,9994 \\
\hline 27 & 0,898884 & 674,1627 & 53 & & 749,9997 \\
\hline
\end{tabular}

* Calculated by the author on the basis of Erlang formulas in MS Excel.

Businessmen can make an arrangement about number of rooms each player will open, but this does not mean that each player will open the agreed number of rooms. It is important to remember that participants can not increase the number of rooms or even reduce the number of opened rooms. The amount of profit or loss each number will bring at this moment depends on the total number of rooms opened by all participants of the game. However, if more than 75 rooms are opened, then all participants will suffer losses, because the maintenance of 75 rooms will cost players more than 750,000 rubles, and the total revenue from servicing 750 people is also 750,000 rubles.

The goal of the game is to make players aware with the principles of the queuing system with failures and check the following collective decisions: whether players will collude, whether players will strive to open such a number of rooms that may provide the maximum total profit of the system and when the Nash equilibrium will be reached. 


\section{Results}

The game was played repeatedly, and the example given reflects the behavior of already experienced players. The students were divided into six teams, i.e. six players were formed. The game moves are shown in table 2 .

Table 2. Results of the game held among students

\begin{tabular}{|c|c|c|c|c|c|c|c|c|c|}
\hline \multirow[t]{2}{*}{ Move } & \multicolumn{6}{|c|}{ Players } & \multirow[t]{2}{*}{$\mathbf{N}$} & \multirow[t]{2}{*}{$\mathbf{A}$} & \multirow[t]{2}{*}{$\mathbf{A} / \mathbf{N}$} \\
\hline & 1 & 2 & 3 & 4 & 5 & 6 & & & \\
\hline 1 & 6 & 10 & 5 & 7 & 4 & 10 & 42 & 749,6165 & 17,84801 \\
\hline 2 & 10 & 11 & 9 & 8 & 5 & 15 & 58 & 750 & 12,93103 \\
\hline 3 & 8 & 13 & 14 & 8 & 4 & 18 & 65 & 750 & 11,53846 \\
\hline 4 & 8 & 14 & 15 & 6 & 4 & 15 & 62 & 750 & 12,09677 \\
\hline 5 & 7 & 16 & 16 & 11 & 4 & 20 & 74 & 750 & 10,13514 \\
\hline 6 & 12 & 16 & 17 & 7 & 2 & 18 & 72 & 750 & 10,41667 \\
\hline 7 & 16 & 18 & 18 & 9 & 6 & 17 & 84 & 750 & 8,928571 \\
\hline 8 & 10 & 18 & 20 & 7 & 5 & 20 & 80 & 750 & 9,375 \\
\hline 9 & 6 & 19 & 18 & 6 & 5 & 15 & 69 & 750 & 10,86957 \\
\hline
\end{tabular}

The theoretical maximum profit of the formed QS is 410,547.6 rubles, at $\mathrm{N}=30(\mathrm{~A}=$ $710,5476)$. In other words, the revenue from servicing A rooms is 710,547.6 rubles, and the cost of maintaining $\mathrm{N}=30$ rooms is 300,000 rubles. During the game, players did not receive such a total profit. Moreover, on the $7^{\text {th }}-8^{\text {th }}$ moves, they opened more than 75 numbers, because of what the rooms brought losses. The $\mathrm{A} / \mathrm{N}$ value in Table 2 reflects revenue from the first room.

Table 3. Results of the game held among students

\begin{tabular}{|c|c|c|c|c|c|c|c|c|}
\hline \multirow{2}{*}{ Move } & \multicolumn{5}{|c|}{ Players } & N & A & A/N \\
\cline { 2 - 9 } & $\mathbf{1}$ & $\mathbf{2}$ & $\mathbf{3}$ & $\mathbf{4}$ & $\mathbf{5}$ & & & \\
\hline 1 & 9 & 10 & 10 & 5 & 7 & 41 & 749,3554 & 18,3 \\
\hline 2 & 7 & 10 & 10 & 7 & 9 & 43 & 749,7771 & 17,4 \\
\hline 3 & 15 & 25 & 10 & 8 & 11 & 69 & 750 & 10,9 \\
\hline 4 & 17 & 1 & 9 & 5 & 10 & 42 & 749,6165 & 17,8 \\
\hline 5 & 25 & 15 & 12 & 5 & 11 & 68 & 750 & 11 \\
\hline 6 & 26 & 15 & 12 & 9 & 10 & 72 & 750 & 10,4 \\
\hline 7 & 28 & 15 & 12 & 13 & 10 & 78 & 750 & 9,6 \\
\hline
\end{tabular}

Let's give an example of another real game (table 3) with five players. Again, on the 7 th move players opened more than 75 numbers, because of what the rooms brought losses.

\section{Conclusion}

Thus, the following conclusions can be made. The offered game based on the QS can be used to test hypotheses of a laboratory economic experiment. Players do not even try to explain to each other the need of opening a small number of rooms, in which the collective profit is maximum. In the pursuit of increasing their own profit, players most often do not stop in increasing their number of rooms, as long as it makes a profit. Only after the appearance of losses, players begin to think about reducing the number of opened rooms. After the 9th move, most players were leaning towards not changing the number of rooms in the next move, and so the game was stopped. This cannot be considered an optimal (according to Nash), but practice has shown the following: when the game continues after 
situations where most players do not want to change the number of rooms, interest in the game quickly wanes, as the result of the game is largely already predetermined at the initial stages, where the distributed profit is maximum.

\section{References}

1. Manakhova I.V. Povedencheskaya ekonomika [Behavioral Economics]. Saratov.. (2017). (In Russ.)

2. Vechkanov G.S. Ekonomicheskaya teoriya: uchebnik dlya vuzov [Economic theory]. St. Petersburg, (2016). (In Russ.).

3. Charness, Gary, Ryan Oprea, and Sevgi Yuksel. "How do people choose between biased information sources? Evidence from a laboratory experiment." Journal of the European Economic Association (2018).

4. Sauer, Petr, Kolinsky Oondrej, and Prasek Jan. "Negotiating municipalities-industrial factory wastewater treatment coalition project: An economic laboratory experiment." Journal of Environmental Protection and Ecology 20.1 (2019): 369-375.

5. Chazov E.L., Grahov V.P., Simchenko O.L. Strategicheskaya model' optimizatsii potokov nalichnosti, ispol'zuyemaya pri upravlenii effektivnost'yu promyshlennogo predpriyatiya $\mathrm{v}$ usloviyakh izmeneniy fakto- rov vneshney sredy [Strategic cash flow optimization model used to manage the efficiency of an industrial enterprise in the face of changes in environmental factors]. Fundamental'nyye issledovaniya [Fundamental Research], 2018, no. 8, pp. 127-130. (In Russ.).

6. Ketova K.V., Rusyak I.G., Vavilova D.D. Mathematical modeling and neural network prediction of the structure and dynamics of human capital of the Russian Federation. Tomsk State University Journal of Control and Computer Science, 2020, no. 53, pp. 13-24. DOI:10.17223/19988605/53/2.

7. Saakyan G.R. Teoriya massovogo obsluzhivaniya [The theory of mass service]. Shakhty, (2006). (In Russ.).

8. Angelovski, Andrej, Jordi Brandts, and Carles Solà. "Equal and unequal profit sharing in highly interdependent work groups: A laboratory experiment." Journal of Economic Behavior \& Organization 184 (2021): 232-252.

9. Petushkov G.V. Evaluation and reliability prediction for highly reliable software and hardware systems: The case of data processing centers. Russian Technological Journal. 2020; 8(1):21-26. (In Russ.) https://doi.org/10.32362/2500-316X-2020-8-1-21-26

10. Pryshchepa, Oksana, et al. "Optimization of multi-channel queuing systems with a single retail attempt: Economic approach." Decision Science Letters 9.4 (2020): 559564. 